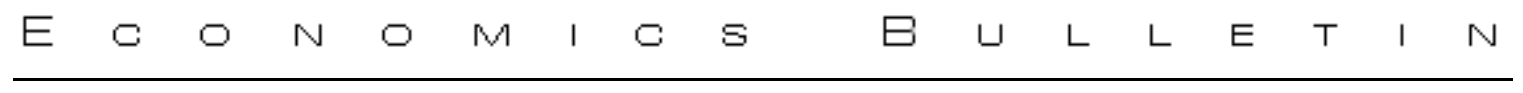

\title{
On the incentive effects of damage averaging in tort law
}

\author{
Tim Friehe \\ Eberhard Karls University, Tübingen
}

\begin{abstract}
It has been generally accepted for unilateral-care models that care incentives are not affected by the use of either accurate damages or average damages if injurers lack knowledge of the precise damage level they might cause. This paper shows that in bilateral-care models with heterogeneous victims, consequences of averages as damage measure are critically dependent on the weighing of respective harm levels. Importantly, we establish that there is an average measure which allows the attainment of efficient care in the bilateral-care framework.
\end{abstract}

I thank Florian Baumann and Laszlo Goerke for discussions on the topic. Helpful comments by an anonymous referee are gratefully acknowledged.

Citation: Friehe, Tim, (2007) "On the incentive effects of damage averaging in tort law." Economics Bulletin, Vol. 11, No. 2 pp. $1-7$

Submitted: March 13, 2007. Accepted: March 13, 2007.

URL: http://economicsbulletin.vanderbilt.edu/2007/volume11/EB-07K10002A.pdf 


\section{Introduction}

The optimal functioning of tort liability critically depends on efficient damage awards (Arlen 2000). However, courts cannot always calculate victim damages correctly and without cost. Court errors in estimating damages and administrative costs for the accurate determination of damages are important factors that may plague tort liability. Dari Mattiacci (2005) and Singh (2003), for instance, analyze the effects of biased court errors in assessing victim damages under different liability rules. Regarding administrative costs, Kaplow and Shavell (1996), using a unilateral-care model, find that if injurers do not know harm ex ante, care incentives are unaffected by the court's choice between accurate and expected damages. Then, administrative costs necessary for the accurate assessment can be saved because accuracy does not influence injurer behavior and, therefore, is costly without associated gain. We approach this same question by inquiring whether using the harm average as the damage measure also leaves injurer incentives unaffected in the accident model with bilateral care. This is of interest as the assumption of bilateral care applies to more real-life contexts than that of unilateral care. Furthermore, the use of the average is not only a matter of theoretical inquiry since damage averaging is actually applied in class action suits. ${ }^{1}$

The fact that both parties can take care complicates the analysis. It is no longer unambiguous how the average to be used as damage measure ought to be constructed and no longer clear whether damage averaging continues to be irrelevant for the outcome. This paper establishes that there are different ways of weighing individual harm levels which correspond to different outcomes. Very importantly, we find that there is an average measure available which allows for the efficient outcome.

In Section 2, we first lay out the model used. Next, we provide the analysis of different average measures. Subsequently, we discuss assumptions used in that analysis, namely standard care by victims and courts observing victim type. Section 3 concludes.

\section{The Model and Analysis}

\subsection{The Model}

The model is based on the standard tort model (see, e.g., Shavell 1987). All parties are riskneutral. Injurers are identical and decide on continuous care $x$ with unit costs of one. We consider two victim types. Victim type $j, j=L, H$, can take continuous care $y_{j}$ with unit costs of one. Victims are identical except for their density function on the support of damages, $d \in[\underline{d}, \bar{d}]$. The high-damage victim has more cumulative density on higher damage magnitudes, causing her expected value of damages to be higher than the expected value of the low-damage type, $E[d, H]=D_{H}>D_{L}=E[d, L] .^{2}$ Neither injurers nor victims can anticipate the precise level of damages that would follow from an accident. Furthermore, injurers cannot foresee the victim type they might harm. Care reduces the accident probability $p\left(x, y_{j}\right)$ at a decreasing rate, i.e., $p_{y_{j}}\left(x, y_{j}\right), p_{x}\left(x, y_{j}\right)<0<p_{y_{j} y_{j}}\left(x, y_{j}\right), p_{x x}\left(x, y_{j}\right)$ holds. We assume that injurer and

\footnotetext{
${ }^{1}$ Given different individual damage levels, this practice - inter alia - affects who intitiates a class action suit (Marceau and Mongrain 2003) and the composition with respect to damage levels of the class action (Che 1996).

${ }^{2}$ The use of stochastic damages separates the type identification from the damage level assessment.
} 
victim care are substitutes with respect to the accident probability, $p_{x y_{j}}\left(x, y_{j}\right)>0 .{ }^{3}$ The liability rule in place is strict liability with a defense of contributory negligence. ${ }^{4}$ Parties are completely informed about their expected payoffs and the applicable legal standard. Care levels are observable and verifiable in court in the case of litigation. Shares of different victim types, $\alpha$ as low-damage and $(1-\alpha)$ as high-damage victim fraction, are common knowledge. The social goal is the minimization of total social costs, consisting of precaution costs and expected harm.

\subsection{Analysis}

Following Kaplow and Shavell (1996), we assume that injurers cannot anticipate which victim type they might harm. This, along with our assumption of stochastic damages, prevents the attainment of the first-best, in which care choices are tailored to the damage level (see also Ganuza and Gomez 2005). Accordingly, social costs are defined as follows

$$
S C\left(x, y_{L}, y_{H}\right)=x+\alpha y_{L}+(1-\alpha) y_{H}+\alpha p\left(x, y_{L}\right) D_{L}+(1-\alpha) p\left(x, y_{H}\right) D_{H}
$$

Socially optimal care levels $x^{*}, y_{L}^{*}$ and $y_{H}^{*}$ solve the first-order conditions of the associated minimization problem. ${ }^{5}$ It holds that $y_{L}^{*}<y_{H}^{*}$ since $\frac{d y^{*}}{d D}=-\frac{p_{y}}{p_{y y} D}>0$.

Individuals minimize the sum of private care costs and expected liability. Due care is assumed to equal the efficient level for the respective victim types $y_{j}^{*}$. The victim type is observable in court, whereas the accurate damage magnitude is not. ${ }^{6}$ If victims are accurately compensated by injurers, established reasoning shows that victims take due care and injurers choose $x^{*}$. However, the efficient outcome $\left(x^{*}, y_{L}^{*}, y_{H}^{*}\right)$ may result in this setting even without spending on the accurate assessment of damages. If type-specific expected harm is used instead of accurate damages and $y_{j}=y_{j}^{*}$, the efficient-care equilibrium is attained. This results because the first-order condition of the injurer is the same as in the case of accurate damage assessment. Hence, the result of Kaplow and Shavell (1996) can be carried forward to the bilateral frame, with due qualification.

We now turn to damage averaging, as average harm is usually referred to in the literature. ${ }^{7}$ Above, we argued that type-specific expected harm attains the efficient outcome. To realize the difference between an average measure which is applied across the board and using typespecific expected harm, imagine that the number of victim types approaches infinity. Then, in

\footnotetext{
${ }^{3}$ This assumption eases our analysis, especially with respect to the discussion of victim incentives, and is quite usual in the literature (e.g., Miceli 1997, p. 18).

${ }^{4}$ This liability rule entails compensation made in equilibrium, which is important for our interest. Negligence allows for efficient care. If injurers adhere to the standard, respective victim types optimize given their full damage and standard injurer care without consequence of the compensatory measure. Similarly, negligence induces efficient care more often than strict liability in a context of errors in measuring damages (e.g., Miceli 1997, p.35).

${ }^{5}$ The specification of $p\left(x, y_{j}\right)$ suffices for the second-order conditions.

${ }^{6}$ Consider the following example. Highly educated individuals are more likely to suffer higher losses in earnings than poorly educated persons. The educational status is easily observed as part of the trial proceedings, whereas the assessment of accurate damages requires reliance on costly experts and the like.

${ }^{7}$ For instance, Arlen (2000, p. 717) states "Injurers can be optimally deterred by basing damages on the average harm caused.", while Dari Mattiacci (forthcoming) notes "accuracy is needed if parties can foresee the magnitude of the harm; if parties face average expectations, average compensation is cheaper than, and as effective as, accurate compensation."
} 
the latter case, courts would use an infinite number of compensation measures, whereas there is only one uniform measure with damage averaging.

In the following, we assume that victims stick to their type-specific due care. This assumption is discussed explicitly in the next section.

It is important to note that there are different ways to average harm over victim types. First of all, there has to be an incorporation of victim-type shares. This leads to

$$
D_{0}=\alpha D_{L}+(1-\alpha) D_{H}
$$

Secondly, we may wish to account for the fact that different victim types might take different levels of care. Different levels of victim care result in different accident probabilities. This has its consequences for the observed average $\widetilde{D}$, which accounts for respective accident probabilities, and is given by

$$
\widetilde{D}=\frac{\alpha p\left(\bar{x}, \overline{y_{L}}\right) D_{L}+(1-\alpha) p\left(\bar{x}, \overline{y_{H}}\right) D_{H}}{\alpha p\left(\bar{x}, \overline{y_{L}}\right)+(1-\alpha) p\left(\bar{x}, \overline{y_{H}}\right)}
$$

where $\bar{x}$ and $\bar{y}_{j}$ represent equilibrium care levels. Note that $D_{0}$ and $\widetilde{D}$ are the same as long as different victim types take the same level of precaution. ${ }^{8}$

The efficiency characteristics of average measures are at the heart of our study and summarized in the following proposition.

Proposition 1 Suppose injurers cannot anticipate victim type, victim types are observable in court, and victims choose $y_{j}=y_{j}^{*}, j=L, H$, then

(a) damage averaging distorts injurer care incentives, unless the average measure equals $D^{*}=$ $\frac{\alpha p_{x}\left(x^{*}, y_{L}^{*}\right) D_{L}+(1-\alpha) p_{x}\left(x^{*}, y_{H}^{*}\right) D_{H}}{\alpha p_{x}\left(x^{*}, y_{L}^{*}\right)+(1-\alpha) p_{x}\left(x^{*}, y_{H}^{*}\right)} ;$

(b) injurers exert more care than the socially optimal level $x^{*}$, if (i) $D_{0}$ is used as average measure, and (ii) $\frac{\partial \epsilon_{p x}\left(x, y_{j}\right)}{\partial y_{j}}>0$ holds in the case $\widetilde{D}$ is used as average measure (with $\epsilon_{p x}$ as elasticity of the accident probability with respect to injurer care);

(c) the individual marginal benefit of injurer care is greater for the average measure $D_{0}$ than for $\widetilde{D}$.

Proof. (a) Given marginal costs of injurer care of 1 , injurers choose the same care level with a damage average as with accurate damages if the marginal benefit of injurer care is larger than (equal to/ less than) 1 for $x<(=/>) x^{*}$. We equate the marginal benefit of injurer care given accurate damages with that given the damage measure $D^{*}$

$$
-\alpha p_{x}\left(x^{*}, y_{L}^{*}\right) D_{L}-(1-\alpha) p_{x}\left(x^{*}, y_{H}^{*}\right) D_{H}=-\alpha p_{x}\left(x^{*}, y_{L}^{*}\right) D^{*}-(1-\alpha) p_{x}\left(x^{*}, y_{H}^{*}\right) D^{*}
$$

and solve for $D^{*}$, which has required properties. Note that $D^{*}=D_{0}$ if $p_{x y_{j}}\left(x, y_{j}\right)=0$ holds.

(b) (i) We evaluate the first-order conditions for injurer care at $\widehat{x}$ which solves the condition if $D_{0}$ is used.

$$
-\alpha p_{x}\left(\widehat{x}, y_{L}^{*}\right) D_{L}-(1-\alpha) p_{x}\left(\widehat{x}, y_{H}^{*}\right) D_{H} \neq-\alpha p_{x}\left(\widehat{x}, y_{L}^{*}\right) D_{0}-(1-\alpha) p_{x}\left(\widehat{x}, y_{H}^{*}\right) D_{0}(=1)
$$

\footnotetext{
${ }^{8}$ Shavell (1987, p. 152) states for the unilateral case "If ...the magnitude of liability for an accident equals ... expected losses conditional on the occurrence of an accident, then liable injurers ... will be led to act optimally under liability rules." By using $\widetilde{D}$, we set liability equal to the expected loss conditional on the occurrence of an accident.
} 
We insert $D_{0}=\alpha D_{L}+(1-\alpha) D_{H}$ and simplify to reach $p_{x}\left(\widehat{x}, y_{L}^{*}\right) \neq p_{x}\left(\widehat{x}, y_{H}^{*}\right)$. The marginal effect of injurer care on the accident probability is absolutely larger for lower victim care levels if injurer and victim care are substitutes. Thus, injurers exert more care if $D_{0}$ is used as a compensation measure. (ii) Proceeding similarly to (i), with $\bar{x}$ solving the first-order condition for $x$ if $\widetilde{D}$ is used, the condition we find after simplification is $\epsilon_{p x}\left(\bar{x}, y_{L}^{*}\right)=\frac{\bar{x}}{p\left(\bar{x}, y_{L}^{*}\right)} p_{x}\left(\bar{x}, y_{L}^{*}\right) \neq$ $\frac{\bar{x}}{p\left(\bar{x}, y_{H}^{*}\right)} p_{x}\left(\bar{x}, y_{H}^{*}\right)=\epsilon_{p x}\left(\bar{x}, y_{H}^{*}\right)$. Larger care if the average measure $\widetilde{D}$ is used, identified by $\left|\epsilon_{p x}\left(x, y_{L}^{*}\right)\right|>\left|\epsilon_{p x}\left(x, y_{H}^{*}\right)\right|$, can only result for substitutional care.

(c) We proceed as above, that is we relate the marginal benefit of injurer care when using $D_{0}$ and when using $\widetilde{D}$ at $x=\bar{x}$. After simplification, we get $\alpha(-1) p_{x}\left(\bar{x}, y_{L}^{*}\right)>(1-\alpha) p_{x}\left(\bar{x}, y_{H}^{*}\right)$.

Comments: (a) If victims can be held to type-specific standards, it is not efficient to use average expectations concerning damages unless the marginal damage average $D^{*}$ is available and employed. The marginal damage average differs from the observed average $\widetilde{D}$ in that the first derivative of the accident probability function with respect to injurer care is used instead of the absolute level. This ensures that care incentives at the margin are not distorted. Substitutional care is usually assumed in the literature (e.g., Ganuza and Gomez 2005) and is sufficient (necessary) for supraoptimal injurer care in response to damage averaging with $D_{0}$ $(\widetilde{D})$. Note that the marginal effect of injurer care on the accident probability function being dependent on the level of victim care is critical for our results. If, for instance, $p\left(x, y_{j}\right)=$ $q(x)+r\left(y_{j}\right)$ holds, then the simplest average measure $D_{0}$, which only allows for respective victim fractions, suffices for efficiency. (b) The divergence in care incentives originates from the fact that the marginal reaction of expected liability to injurer care is no longer equal to the response of expected damages to care. The injurer needs to incorporate the fact that victims with higher (lower) damage potential take more (less) care, as she does under full compensation. The different levels of victim care imply different levels of productivity of injurer care with respect to its application to the accident probability function of low-damage and high-damage victims. (c) With substitutional care, $\widetilde{D}$ is preferable to $D_{0}$ as the arising distortion in injurer care is smaller.

\subsection{Discussion}

\subsubsection{Victim Incentives to Comply in the Case of Damage Averaging}

Both victim types know that if they take due care, they will be compensated by the amount of the average measure used $\bar{D}, \bar{D} \in\left\{D_{0}, \widetilde{D}, D^{*}\right\}$, whereas they will be punished for suboptimal care by no compensation. Regarding victim care, the use of average damages as a compensation measure, on the one hand, questions the optimality of due care for the high-damage victim because the usual discontinuity in victim costs at efficient care is weakened by the fact that compensation does not cover full harm. On the other hand, we need to acknowledge that lowdamage victims not only recover full harm but actually gain something. Indeed, the size of the respective differences that the victims bear if they take at least standard care is $D_{H}-\bar{D}>0$ and $D_{L}-\bar{D}<0$. 
The victim cost function of type $j$ is

$$
V C_{j}(x, y)= \begin{cases}y_{j}+p\left(x, y_{j}\right)\left(D_{j}-\bar{D}\right) & y_{j} \geq y_{j}^{*} \\ y_{j}+p\left(x, y_{j}\right) D_{j} & y_{j}<y_{j}^{*}\end{cases}
$$

The injurer cost function depends on the care choices of both victim types in the following way

$$
I C(x, y)= \begin{cases}x & y_{H}<y_{H}^{*} \text { and } y_{L}<y_{L}^{*} \\ x+\alpha p\left(x, y_{L}\right) \bar{D} & y_{H}<y_{H}^{*} \text { and } y_{L} \geq y_{L}^{*} \\ x+(1-\alpha) p\left(x, y_{H}\right) \bar{D} & y_{H} \geq y_{H}^{*} \text { and } y_{L}<y_{L}^{*} \\ x+\alpha p\left(x, y_{L}\right) \bar{D}+(1-\alpha) p\left(x, y_{H}\right) \bar{D} & y_{H} \geq y_{H}^{*} \text { and } y_{L} \geq y_{L}^{*}\end{cases}
$$

The injurer minimizes individual costs with respect to care given victim care. No care is chosen if $y_{H}<y_{H}^{*}$ and $y_{L}<y_{L}^{*}$ hold. Suppose only one victim type adheres to the standard, for instance, the low-damage type. The injurer chooses $x^{\prime \prime}=\arg \min \left\{x+\alpha p\left(x, y_{L}^{*}\right) \bar{D}\right\}$ with $x^{\prime \prime}$ smaller than $x^{*}$. The same argument applies if only the high-damage victim adheres to the behavioral standard. Finally, consider the case $y_{H} \geq y_{H}^{*}$ and $y_{L} \geq y_{L}^{*}$. We can conceive of $x$ being greater than, equal to or less than $x^{*}$.

We reason in three steps what victim decisions can be expected.

(1) It is never optimal for victims to respond with $y_{j}<y_{j}^{*}$ to $x \leq x^{*}$. The minimization of the respective victim cost function yields that it is preferable to choose at least standard care because $\hat{y}_{j}=\arg \min \left\{y_{j}+p\left(x, y_{j}\right) D_{j}\right\}$ is greater than or equal to $y_{j}^{*}$ if $x \leq x^{*}$. In addition, adherence to standard care yields at least some compensation. We stated above that if only one victim type exerts at least standard care, the injurer takes care less than $x^{*}$. Thus, there is no equilibrium in which at least one victim is negligent and the injurer takes care less than $x^{*}$. (2) It is possible that victims respond with substandard care to injurer care being substantially larger than $x^{*}$. However, the injurer responds individually optimal to victims being negligent by lowering care below $x^{*}$. According to (1), victims respond to this by increasing their care to at least standard levels. Consequently, there may exist only a mixed strategy equilibrium if the injurer responds to victim standard care by very large $x>x^{*}$ which is reciprocated by a drop in victim care. ${ }^{9}$ To exclude this possibility requires assuming the following: It holds that $\left[p\left(x, \hat{y}_{j}\right)-p\left(x, y_{j}^{*}\right)\right] D_{j}>y_{j}^{*}-\hat{y}_{j}-p\left(x, y_{j}^{*}\right) \bar{D}$ for any $x>x^{*}$ and $\bar{D}$. This states the following. The care choice $x>x^{*}$ lowers the incentive for victims to exert care. It is true that for $x>x^{*}$, it holds that $-\frac{\partial p\left(x, y_{j}^{*}\right)}{\partial y_{j}} D_{j}<1$. Then, the increase in victim care from $\hat{y}_{j}$ to $y_{j}^{*}$ is not worthwhile as long as the effect of $\bar{D}$ is ignored. Relating this to the assumption, the difference in probabilities weighted with the respective damage $D_{j}$ is lower than the difference in care levels $y_{j}^{*}-\hat{y}_{j}$. The assumption declares that taking the compensation $\bar{D}>D_{L}$ into account makes the investment in victim care cost-justified. Consequently, there is no mixed strategy equilibrium if we exclude cases in which the difference in care levels is not sufficiently weakened by the compensation $\bar{D}$ as to make standard care preferable. This will not be restrictive except for rather extreme contexts. Consolidating the arguments made in (1) and (2), we conclude that, by and large, there is no equilibrium in which victims do not exert at least standard care.

(3) It may be that $x<x^{*}$ results for $y_{H} \geq y_{H}^{*}$ and $y_{L} \geq y_{L}^{*}$. The low-damage victim certainly does not take more than standard care since $D_{L}-\bar{D}<0$. However, the high-damage victim

\footnotetext{
${ }^{9}$ See Endres and Querner (1995) for a closer description of such a case of circularity in tort law.
} 
might prefer to take care beyond the standard. The first-order condition of the high-damage victim, given $y_{H} \geq y_{H}^{*}$, is given by $-\frac{\partial p\left(x, y_{H}\right)}{\partial y_{H}}\left(D_{H}-\bar{D}\right)=1$. There are two effects: First, due to low injurer care, $x<x^{*}$, the absolute value of the partial derivative of the probability function is larger than that in the first-order condition of the social problem with $x^{*}$. This indicates an increase in the incentive to take care for the high-damage victim. Second, this increase is at least partially offset by $D_{H}-\bar{D}<D_{H}$. So, if care chosen by the injurer does not deviate too strongly from $x^{*}$, which contains the first effect, or if $\bar{D}$ is sufficiently different from $D_{H}$, which enforces the second effect, the high-damage victim will stick to standard care $y_{H}^{*}$.

\subsubsection{Information on Type and Magnitude Is Costly}

Assume that courts cannot observe the type without cost. In consequence, courts most likely use one care standard. ${ }^{10}$ The social cost function which reflects that injurers cannot anticipate victim type and that the due care level for victims will apply irrespective of the type reads

$$
S C(x, y)=x+y+\alpha p(x, y) D_{L}+(1-\alpha) p(x, y) D_{H}
$$

Let $\left(x^{\prime}, y^{\prime}\right)$ minimize (8). Within this context, does the use of practical damage averages distort injurer care incentives?

Proposition 2 Suppose injurers cannot anticipate victim type, victim types are not observed in court and victims choose $y_{j}=y^{\prime}, j=L, H$, then injurers will respond in accordance with the social interest to uniform victim care if $D_{0}$ or $\widetilde{D}$ is used as a compensation measure.

Proof. The first-order condition of the injurer given standard victim care is $1+p_{x}\left(x, y^{\prime}\right) \bar{D}=0$. Injurer care incentives are socially optimal if $\bar{D}=D_{0}$. Likewise, incentives are unaffected if $\bar{D}=\widetilde{D}$, as $\widetilde{D}=D_{0}=D^{*}$ in this case.

\section{Conclusion}

Victims frequently differ in their damage levels. In the unilateral-care framework, it does not warp care incentives if the court applies average damages instead of accurate damages in the case in which injurers cannot anticipate the victim type. We consider the accident model with bilateral care. This has an ample effect on the averaging of damages. We establish that two measures which put themselves forward due to their simplicity distort care incentives. However, we also establish that there is an average measure which induces efficient injurer care. The special feature of this measure is that it not only accounts for different levels of victim care but also for their consequences at the margin.

\footnotetext{
${ }^{10} \mathrm{~A}$ uniform care standard in face of agent heterogeneity, labeled reasonable man standard, has been studied in the context of heterogeneous precaution costs. A recent contribution is Miceli (2006).
} 


\section{References}

Arlen, J. (2000), Tort Damages, in: Boudewijn Bouckaert and Gerrit De Geest (eds.), Encyclopedia of Law and Economics, Vol. II, Edward Elgar, 682-734.

Che, Y.-K. (1996), Equilibrium Formation of Class Action Suits, Journal of Public Economics 62, 339-361.

Dari Mattiacci, G. (2005), Errors and the Functioning of Tort Liability, Supreme Court Economic Review 13, 165-187.

Dari Mattiacci, G. (forthcoming), Tort Law and Economics, in: Hatzis, A. (ed.), Economic Analysis of Law: A European Perspective, Edward Elgar.

Endres, Alfred and Immo Querner, (1995), On the Existence of Care Equilibria Under Tort Law, Journal of Institutional and Theoretical Economics, 151(2), 348-357.

Ganuza, J. J. and F. Gomez (2005), Caution, Children Crossing: Heterogeneity of Victim's Cost of Care and the Negligence Rule, Review of Law and Economics 1, Article 3.

Kaplow, L. and S. Shavell (1996), Accuracy in the Assessment of Damages, Journal of Law and Economics 39, 191-209.

Marceau, N. and S. Mongrain (2003), Damage Averaging and the Formation of Class Action Suits, International Review of Law and Economics 23, 63-74.

Miceli, T. J. (1997), Economics of the Law. Torts, Contracts, Property, Litigation, Oxford University Press.

Miceli, T. J. (2006), On Negligence Rules and Self-Selection, Review of Law and Economics 2, Article 1.

Shavell, S. (1987), Economic Analysis of Accident Law, Harvard University Press.

Singh, R. (2003), Efficiency of 'Simple' Liability Rules When Courts Make Erroneous Estimation of the Damage, European Journal of Law and Economics 16, 39-58. 